\title{
Deve-se Dividir a Guanabara em Municipios?
}

\author{
Benedicto Silva \\ Fundador da Escola Brasileira de \\ Administração Pública
}

$\mathrm{N}$

os têrmos da Constituição Federal (artigo $4^{\circ}$ das Disposições Constitucionais Transitórias), ao efetuar-se a mudança da Capital da República para Brasilia, o antigo Distrito Federal transformou-se automàticamente no atual Estado da Guanabara.

A cidade do Rio de Janeiro, uma das grandes metrópoles do hemisfério, tão decantada em todo o globo em virtude de suas espetaculares belezas naturais, perdeu as insignias de capital do maior país latino-americano e passou a ser simplesmente capital do Estado emergente.

Surgiu, assim, na República dos Estados Unidos do Brasil. mais uma unidade federativa autônoma, com a singularidade de ser, ao mesmo tempo, a de menor área territorial $(1.171 \mathrm{~km} 2)$ e maior densidade demográfica $(2.824,22$ hab. por $\mathrm{km} 2)$.

Tradicionalmente, os Estados brasileiros caracterizam-se pelo conteúdo municipal. Todos são divididos em municípios. Cada Estado é, por assim dizer, uma soma de parcelas municipais. O município brasileiro típico, por sua vez, é um país em miniatura: compõe-se de uma área rural, alguns povoados, erigidos ou não em distritos, e a cidade-sede, que faz as vêzes de capital do município.

Como que navegando nas águas dos Estados existentes, o da Guanabara também teve bem presente, ao elaborar sua Constituição, o problema da divisão municipal, apesar da pequenez da base física.

Numerosas disposições da Constituição do Estado pressupõem, indiciam, ou mesmo propiciam a criação de municipios. O Capitulo II, por exemplo, que trata (Seção II) das atribuições da Assembléia Legislativa, contém as seguintes:

"Art. 5o Compete exclusivamente à Assembléia Legislativa:

V - aprovar a escolha do Prefeito da Capital, do Procurador-Geral da Justiça, dos Ministros do Tribunal 
de Contas e dos membros do Conselho de Contribuintes;

$\mathrm{XI}$ - deliberar sôbre a incorporação, subdivisão ou desmembramento do território do Estado, para anexação a outro ou formação de nôvo Estado, anteriormente a plebiscito, e com posterior aprovação do Congresso Nacional;

XIV - autorizar acôtdos e convênios celebrados pelo Governador com a União, outro Estado ou Municipio e ratificar os que forem negociados, por motivos de imperiosa urgência, sem essa autorização;

XV - autorizar o Governador a decretar a intervenção em Municipio".

A Seção III do Capitulo II, que trata das leis e resoluções da Assembléia Legislativa, dispõe:

"Art. 9: A Assembléia deliberará:

III - por maioria absoluta de votos dos seus membros, para recebimento da representação contra o Governador e para aprovação de projetos:

b) de transferência de impostos estaduais para os Municipios;

IV - por dois terços $(2 / 3)$ dos seus membros. para destituição do Governador e aprovação de projetos sôbre:

a) criação de Municipios, subdivisão ou desmembramento do Estado ou Municipios, assim como incorporação do território, no todo ou em parte, a outro Estado, ou formação de nôvo Estado";

A Seção V do mesmo Capítulo, que trata dos direitos e deveres dos Deputados, estabelece:

"Art. 16. E' permitido ao Deputado, independentemente de licença da Assembléia:

b) afastar-se temporàriamente do mandato para exercer as funções de Ministro de Estado, Interventor 
Federal, Secretário de Estado, Prefeito da Capital ou missão oficial no exterior".

A Seção VI, que trata do orçamento, determina:

"Art. 19. O orçamento observará, além do disposto nos arts. 73 a 75 da Constituição Federal, os preceitos seguintes:

XIV - O Estado e os Municipios adotarão uma politica, em relação ao pessoal, que os leve a não despender anualmente com o funcionalismo público, civil ou militar, mais de $60 \%$ de suas rendas".

A Seção II do Capitulo III, que trata das atribuições do Governador do Estado, diz:

"Art. 30. Compete privativamente à Governador do Estado:

VI - celebrar acôrdos e convênios com os órgãos da União, de outros Estados e Municipios, ad referendum da Assembléia Legislativa, ou nos têrmos das autorizações prèviamente concedidas (art. 5․, XIV);

IX - executar a intervenção nos Municipios, quando determinada pela Assembléia Legislativa, nos casos previstos na Constituição Federal";

A Seção III do mesmo Capitulo II, que dispõe sôbre: a responsabilidade do Governador, declara:

“Art. 31. A Assembléia Legislativa poderá destituir o Governador, na forma desta Constituição se fôr responsabilizado por atos que atentarem contra: nicipio;

I - a existência da União, do Estado ou de $\mathrm{Mu}$ -

$\S 1$ : O processo de destituição será iniciado pela representação de qualquer órgão do Poder Judiciário, Deputado, Comissão Parlamentar, Partido Politico ou Câmara Municipal". 
O Capitulo IV, que trata dos órgãos do Poder Judiciário, também inclui implicitamente a idéia da divisão territorial do Estado da Guanabara. Com efeito, o $\S 2^{\circ}$ do art. 33 determina:

"A lei ordinária poderá, salvo quanto ao Tribunal de Justiça, limitar a competência territorial de órgãos judiciários, bem como instituir tribunais para julgar em definitivo causas de valor limitado, ou relativas a deternados direitos".

No Título IV - Da Organização Ḿunicipal - a Constituição do Estado da Guanabara fala expressamente na divisão do Estado em municípios, in verbis:

"Art. 52. A divisão do Estado em Municipios será condicionada às peculiaridades da região, às condições geo-econômicas, demográficas e financeiras e às possibilidades de manutenção dos serviços públicos municipais".

O Ato Constitucional das Disposições Transitórias, por sua vez, começa por uma fortemente sugestiva do desdobramento do Estado em municípios. Diz:

"Art. 19 Enquanto não forem criados Municipios no Estado da Guanabara, caberá ao Estado a decretação e a arrecadação dos tributos municipais".

Como se tôdas essas referências à criação ou existência previsível de municípios no Estado da Guanabara não bastassem, o referido Ato Constitucional das Disposições Transitórias trata especificamente do modus faciendi da divisão municipal, estabelecendo métodos, normas e prazos para o seu processamento, in verbis:

"Art. 89 Dentro de 3 (três) meses depois de promulgada a Constituição, será criada uma Comissão composta de 4 (quatro) Deputados indicados pelo Presidente da Assembléia com aprovação do plenário, igualmente representadas a maioria e minoria, e de 4 (quatro) técnicos, designados pelo Governador, para realizar estudos sôbre a organização municipal do Estado.

Art. 90 No dia 21 de abril de 1963, realizar-se-á um plebiscito para decidir, qualquer que seja o parecer da Comissão, sôbre a divisão municipal, dêle podendo participar todos os eleitores inscritos.

Parágrafo único. No prazo de um mês após a apuração dos resultados do plebiscito, a Assembléia to- 
mará as providências necessárias ao pleno cumprimento da deliberação popular".

Como se vê, apesar de a idéia da partição do minúsculo território da Guanabara em municipios autônomos estar presente em tantas seções da Constituição do Estado, a decisão final sôbre a matéria foi transferida do legislador para o povo, mediante recurso do plebiscito que se deverá realizar no dia 21 de abril de 1963.

A Assembléia Legislativa criou, em 1961, a Comissão prevista no artigo $8^{\circ}$ do Ato Constitucional das Disposições Transitórias e denominou-a Comissão Especial sôbre Organização Municipal do Estado. Presidida a princípio pelo Deputado Temístocles Brandão Cavalcanti, hoje pelo Deputado Aliomar Baleeiro, aquela Comissão vê-se a braços com a responsabilidade de empreender e concluir, no decorrer do ano de 1962, e divulgar desde os primeiros resultados de seu trabalho, os estudos sôbre a organização municipal do Estado.

Quaisquer que sejam as conclusões dêsses estudos, o eleitorado da Guanabara será obrigatòriamente convocado para, no dia 21 de abril de 1963, em plebiscito, decidir sôbre a divisão territorial e administrativa do Estado. Em outras palavras: os eleitores serão obrigados, sob as penas da lei, a manifestarem-se sôbre se a Guanabara deve ser dividida e organizada em municipins autônomos, como os demais Estados, ou se deve manter o status de Cidade-Estado, caso em que continuaria a constituir unidade federativa sui-generis, no Brasil.

Não obstante a decisão final depender do pronunciamento coletivo, é evidente que não se deve submeter o problema a plebiscito sem antes esclarecer largamente o eleitorado sôbre as conseqüências, vantagens e desvantagens das alternativas. A Comissão Especial existe precisamente para o fim de identificar e indicar, pela pesquisa idônea, os prós e contras da divisão do Estado em municipios.

Um dos membros técnicos da Comissão Especial, o ex-Deputado Federal Prado Kelly, elaborou e submeteu a seus pares anteprojeto de lei para disciplinar o plebiscito previsto no artigo $9^{\circ}$ do Ato Constitucional das Disposições Transitórias. Transcrevemos, em seguida, os dispositivos dêsse anteprojeto que, se forem aprovados, governarão a realização do plebiscito.

“Art. $2 \circ$ O plebiscito realizar-se-á em 21 de abril de 1963 e obedecerá às instruções que baixar o Tribunal Regional Eleitoral, no uso de sua competência normativa, concernente ao processo e à apuração dos sufrágios (Constituição da República, artigo 119, V). 
$\S 1$. No preparo e na realização do plebiscito se observará, em tudo que fôr aplicável, a legislação eleitoral da União (Constituição da República, art. 5\%, $\mathrm{XV}, \mathrm{a})$.

$\S 2$. Todos os eleitores inscritos no Estado da Guanabara até ao momento de serem organizadas as respectivas listas participarão obrigatòriamente do plebiscito (Constituição da República, art. 133) e responderão à consulta pela forma prevista no $\S 3$ ?

$\S 3 \circ \mathrm{O}$ presidente da mesa receptora fará entrega ao eleitor de cédula oficial, na qual constarão os dizeres seguintes: "E' exequiivel e conveniente a divisão do Estado da Guanabara em Municipios autônomos?", figurando abaixo dois retângulos, encimados das palavras "sim" e "não". nos quais o votante assinalará com uma cruz a sua preferência.

Art. $3^{\circ}$ Se a maioria do eleitorado inscrito concluir pela instituição, em principio, de Municipios, a Assembléia Leg̣islativa exercitará a competência conferida no art. 9: IV, a, da Constituição do Estado, dentro do prazo fixado pelo parágrafo único do art. $9^{\circ}$ do Ato Constitucional das Disposições Transitórias".

Seria altamente desejável que a decisão, embora submetida ao voto popular, se baseasse, tanto quanto possivel, em critérios lógicos, protegendo-se igualmente, tanto quanto possível, contra a intervenção de critérios sentimentais, empiricos ou bairristas, Trata-se, antes de mais nada, não de dividir os $1.100 \mathrm{~km} 2$ do território da Guanabara em municípios microscópicos, mas de saber, de acôrdo com o critério da máxima vantagem social, que mais convém ao Estado: manter sua condição sui-generis de Cidade-Estado, ou dividir seu território em municipios.

No caso de ficar demonstrada a conveniência da divisão municipal, cumpre ainda saber qual o número de municipios em que o Estado deverá ser dividido para fazer o maior bem ao maior número de seus habitantes.

$E^{\prime}$ curial que a tais indagações não se pode responder a ôlho, nem de ouvido E' indispensável que, ao votar "sim" (pela divisão do Estado em municipios), ou "não" (pela manutenção do status quo), o eleitor o faça com conhecimento de causa, escolhendo racionalmente a alternativa que lhe parecer preferivel.

Guiando-se pela especificação dos serviços públicos municipais sistematizada pela Comissão Interamericana de Municípios, 
a Comissão Especial dirigiu-se a numerosas pessoas, inclusive ao autor dêste artigo, para solicitar subsídios informativos e sugestões pertinentes aos estudos de que se acha incumbida.

Segundo os têrmos da comunicação recebida, a Comissão Especial pretendia levar a efeito estudos exaustivos sôbre a conceituação geral de todos os serviços públicos de uma grande metrópole moderna, grupados nas onze categorias seguintes:

\title{
ESQUEMAS DE SERVIÇOS PÚBLICOS MUNICIPAIS
}

\author{
Água potável. \\ Aqueduto. \\ Esgotos. \\ A. Serviços de Higiene....... $\left\{\begin{array}{l}\text { Drenagem. } \\ \text { Asseio o limpeza de ruas, etc. }\end{array}\right.$ \\ Centro de Profilaxia e Prevenção. \\ Morgue ou necrotério. \\ Cemitério. \\ Fiscalização de alimentos.
}

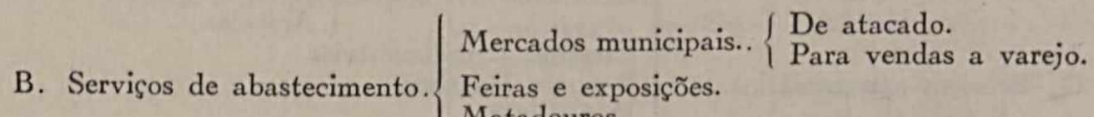
Matadouros

Cooperativas........ \{ De Produção.

C. Serviços Assistenciais...... $\left\{\begin{array}{l}\text { Postos Policiais. } \\ \text { Ambulâncias. } \\ \text { Albergues. } \\ \text { Restaurantes populares. } \\ \text { Postos de Pronto Socorro. } \\ \text { Dispensários. } \\ \text { Hospitais. } \\ \text { Asilcs. } \\ \text { Sanatórios. } \\ \text { Lazaretos. } \\ \text { Funerárias. } \\ \text { Retiros e Pensões. } \\ \text { Outros de Assistência Social. }\end{array}\right.$

D. Serviços de Educação e

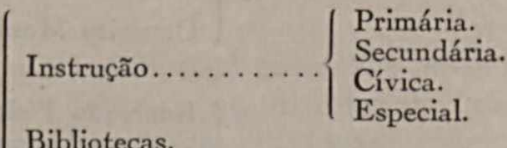

Bibliotecas.

Especial.

Cultura.............

Museus........... $\left\{\begin{array}{l}\text { De Artes. } \\ \text { De Ciências. }\end{array}\right.$

Teatro. Históricos.

Orquestra ou Banda Municipal.

Estações Radiodifusoras.

Conferências.

Concursos.

Concertos.

Zoológicos. 
E. Serviços de Segurança..... $\left\{\begin{array}{l}\text { Polícia. } \\ \text { Incêndios........... } \\ \text { Fiscalização e Inspeção }\left\{\begin{array}{l}\text { Prevenção. } \\ \text { Extinção. }\end{array}\right. \\ \begin{array}{l}\text { Edifícios. } \\ \text { Ascensores. } \\ \text { Máquinas. } \\ \text { Motores. } \\ \text { Veículos. } \\ \text { Espetáculos. }\end{array}\end{array}\right.$

Estabelecimentos Penais.

Estabelecimentos de Correção.

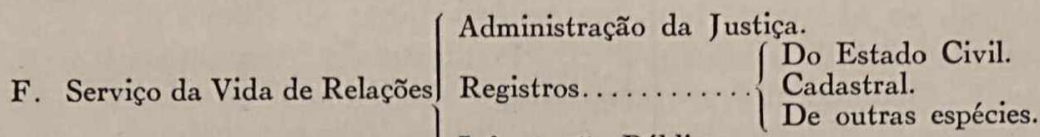

Informação Pública.

Cooperação Intermunicipal.

G. Serviços agropecuários..... $\left\{\begin{array}{l}\text { Granjas............ }\left\{\begin{array}{l}\text { Agrícolas. } \\ \text { Avícolas. } \\ \text { Apícolas. } \\ \text { Estações Experimentais. } \\ \text { Registro Pecuário. } \\ \text { Frigoríficos. } \\ \text { Silos e Armazéns. } \\ \text { Pastos. } \\ \text { Auxílio agropecuário. }\end{array}\right.\end{array}\right.$

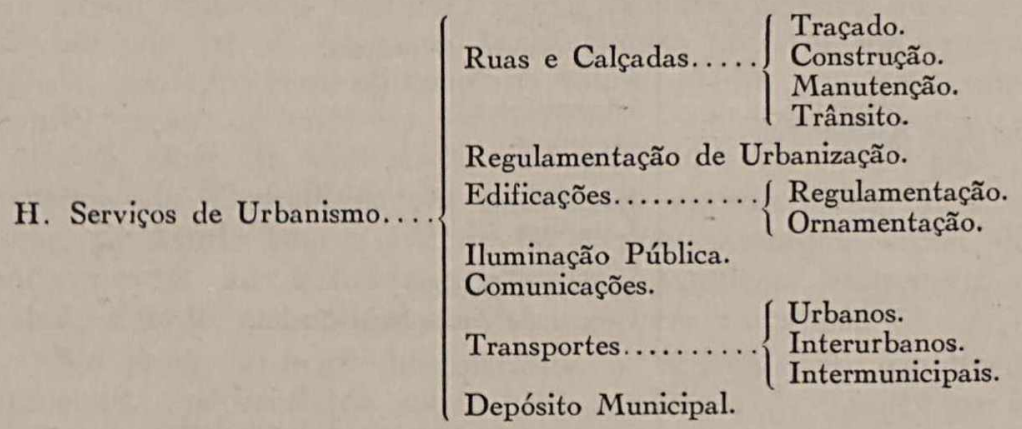

$\mid \begin{aligned} & \text { Educação Física. } \\ & \text { Campos Desportivos. } \\ & \text { Ginásios. }\end{aligned}$

I. Serviços de Recreação...... $\begin{aligned} & \text { Parques. } \\ & \text { Balneários. } \\ & \text { Piscinas. }\end{aligned}$

Hipódromos.

Autódromos.

Cinódromos.

Restaurantes.

Estádio.

Espetáculos Municipais. 
J. Serviços lucrativos......... $\left\{\begin{array}{l}\text { Arrendamento } \\ \text { Vendas. } \\ \text { Emprêsas. } \\ \text { Explorações. } \\ \text { Energia. } \\ \text { Fôrça. } \\ \text { Gás. } \\ \text { Luz. } \\ \text { Loterias. }\end{array}\right.$

L. Serviços por descentralização, delegação ou em combinação com outros organismos, relacionados com:

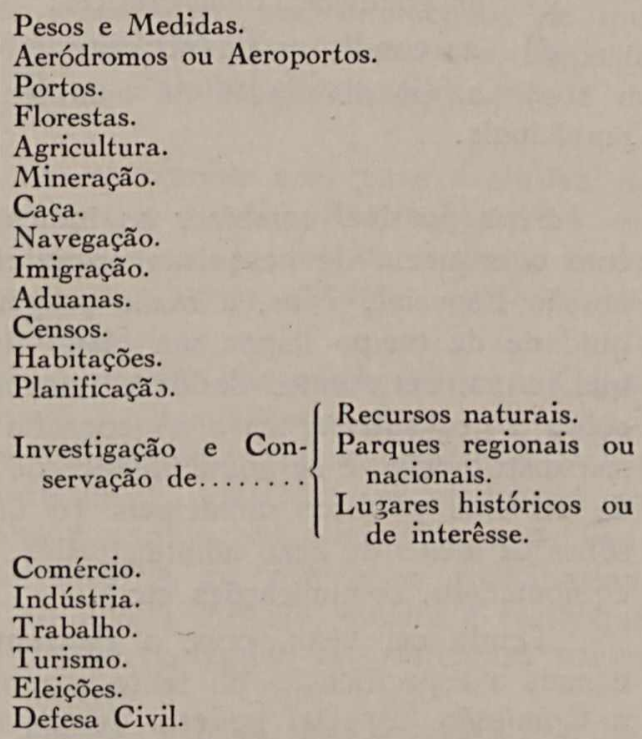

Tais estudos seriam conduzidos à luz do método comparativo, focalizando a experiência de vários países, de modo que se tornasse possivel uma apreciação geral da organização e manutenção dos serviços municipais no Estado da Guanabara.

Se o programa de estudos da Comissão Especial fôsse levado a efeito de acôrdo com êsse esquema, ter-se-ia a mais copiosa documentação sôbre administração metropolitana até agora elaborada em todo o mundo.

Trata-se, com efeito, de formidável plano de pesquisas sôbre administração municipal, no Brasil e no estrangeiro, para determinar a distribuição, a competência, a regulamentação, a prestação, a organização e o financiamento de todos os serviços públicos de caráter local incidentes em uma área metropolitana.

Em face da premência de tempo decorrente da inadiabilidade da data do plebiscito (21 de abril de 1963), foi considerada impraticável a realização de inquéritos tão vastos e tão inclusivos quanto os previstos no esquema adotado pela Comissão Especial.

Qual a alternativa, então? 
Como já vimos, o artigo 52 da Constituição do Estado da Guanabara coloca a criação de municípios na dependência de apreciação de cinco complexos de fatôres: ficos);

a) peculiaridades da região (fatôres possivelmente geográ-

b) as condições geo-econômicas;

c) as condições demográficas;

d) as condições financeiras;

e) as possibilidades de manutenção dos serviços públicos municipais.

Seria possivel combinar as indicações contidas no artigo 52 com o esquema de pesquisas originàriamente adotado pela Comissão Especial. Mas, a razão pragmática e incoercivel da exigüidade de tempo impõe um plano de pesquisas mais modesto, que reúna, entretanto, dados e informações fidedignos e amplos sôbre a geografia física e a geografia econômica, a população e sua distribuição, e as possibilidades de manutenção de um minimo de serviços públicos municipais (o que pressupõe investigações sôbre os meios de ação administrativa: pessoal, dinheiro, material, equipamento, comunicações etc.).

Tendo em vista, pois, a flagrante insuficiência de tempo, e mais a especificação do texto constitucional, considerou-se que a Comissão Especial poderia desempenhar satisfatòriamente sua tarefa, se levasse a efeito estudos compreensivos, profundos e idôneos, porém limitados aos aspectos que acabamos de enumerar.

Nem por haver sido a reponsabilidade da decisão transferida da Assembléia Legislativa para o povo, está o eleitor da Guanabara exonerado da obrigação de votar com sabedoria no plebiscito de 21 de abril de 1963. A simples transferência de competência não bastará para resolver o problema. E' preciso habilitar o eleitorado a decidir bem. Os quase quatro milhões de habitantes da Guanabara têm, assim, o direito de exigir esclarecimentos completos, inteligiveis e fidedignos dos Podêres Públicos do Estado relativamente à issue da municipalização.

Está em jôgo o próprio destino do Estado. Afinal de contas, o Estado da Guanabara, apesar de ser o segundo do pais em arrecadação, era apenas o Distrito Federal até 21 de abril de 1960 , era apenas um municipio, o Município Neutro, desmembrado da antiga província do Rio de Janeiro. Como municipio, o ex-Distrito Federal, hoje Estado da Guanabara, não resiste a confronto territorial com centenas de municipios brasileiros. Em verdade, dos 2.781 municipios existentes no Brasil em 31 de 
dezembro de 1961, 900 são maiores territorialmente do que o Estado da Guanabara.

Se o fator decisivo para a criação de municipios fôsse a extensão territorial é claro que a Guanabara não poderia aspirar sequer à categoria de Estado - faltar-lhe-ia base física para pretender passar de municipio. Por outro lado, se a divisão territorial em municipios autônomos se fizesse em função do efetivo demográfico, a Guanabara poderia ter mais municipios do que qualquer dos Estados seguintes: Alagoas, Amazonas, Espirito Santo, Goiás, Maranhão, Pará, Paraíba, Piauí, Rio Grande do Norte e Sergipe.

O problema, porém, não se resolve com base exclusiva na extensão territorial, ou no efetivo demográfico, ou mesmo em uma combinação de ambas as coisas. $E^{\prime}$ preciso ponderar, medir e sopesar vários fatôres conjugadamente, tal como exige o artigo 52 da Constituição da Guanabara.

A responsabilidade da Comissão Especial sôbre a Organização Municipal do Estado é imensa e iniludivel. E' a responsabilidade de assessorar imparcial e judiciosamente o Poder Legislativo, o Poder Executivo e, sobretudo, o eleitorado da Guanabara no que concerne à escolha da alternativa mais consentânea aos interêsses da maioria da população guanabarina. E essa responsabilidade é tanto mais pesada, quanto é certo que qualquer das alternativas que fôr preferida descontentará vários grupos e suscitará muitas críticas.

Esta é uma daquelas questões que se devem resolver ùnicamente de acôrdo com o cânone da máxima conveniência social.

Se fôr demonstrada que a fragmentação da Guanabara em municípios autônomos fará o maior bem ao maior número de habitantes do Estado - procedamos à divisão municipal, by all means.

Per contra, se os estudos da Comissão Especial provarem que a máxima conveniência social está na manutenção do status quo, então, sem pestanejar, sem um segundo de hesitação tenhamos a clarividência de conservar a Guanabara terijısrialmente una, indivisa - a única Metrópole-Estado do mundo contemporâneo. 